\title{
Toward a scalable and sustainable approach to open access publishing and archiving for humanities and social sciences societies: A proposal
}

\author{
Rebecca KENNISON and Lisa NORBERG \\ K/N Consultants \\ Rebecca Kennison \\ Principal, K/N Consultants \\ Director, Center for Digital Research and Scholarship, Columbia University \\ Email: rrkennison@knconsultants.org \\ Website: http://knconsultants.org/ \\ Lisa Norberg \\ Principal, K/N Consultants \\ Dean of the Library and Academic Information Service, Barnard College \\ Email: Inorberg@knconsultants.org
}

\begin{abstract}
The proposal we offer here (and in the more extensive "white paper" proposal on which this article is based) tackles head-on the open access (OA) business models that have proven particularly problematic for implementation of OA in the humanities and social sciences (HSS). Our proposal suggests all tertiary institutions contribute to systemic support of the research process itself, including its entire scholarly output. A bold rethinking of the economics of OA by way of partnerships among scholarly societies and academic libraries funded by an institutional fee structure based on a studentand-faculty per-capita sliding scale, our plan is nevertheless intentionally incremental. Our proposal focuses first on HSS and primarily in the United States, but just as research and scholarship are increasingly global and collaborative, our plan is not bound by discipline or national borders, but can be adopted by all those looking for a more equitable and sustainable OA model.
\end{abstract}

In the 11 years since the Budapest Open Access (OA) Initiative launched what has now become known as the "OA movement," considerable strides have been made toward widespread adoption of the principles of OA. Practice, however, has lagged behind as both credibility and business models have struggled to gain traction. The transition to OA from subscription-based society publishing operations in humanities and social sciences (HSS) has been particularly difficult, for reasons that expose the limitations of the most prevalent OA models: for HSS researchers, articles are not the only publication type of value or even the most valued type of publication; external funding for HSS research, particularly in the United States, is minimal or non-existent; many HSS societies consider their publications to be the primary benefit they offer their members and find it difficult to imagine how they would support their society's activities if their current publishing operation were to change.

The predominant system of OA funding, with its emphasis on article- or object-level charges, works somewhat well in disciplines in which research is well funded and the output that is rewarded is primarily peer-reviewed articles. Even in those disciplines, however, research output (especially data) supported by funding goes beyond that of peer-reviewed articles. Our proposal, summarized here, tackles head-on the major drawbacks to the article-processing charge (APCs) model; rather than relying on single-unit payments made by individuals for only certain types of publication, our model looks to all tertiary institutions to contribute to systemic support of the research process itself, including (but not limited to) its entire scholarly output, whether article, monograph, dataset, 
conference presentation, or format not yet envisioned. Our model likewise looks to societies to play a central, rather than peripheral, role within the scholarly communication ecosystem, and asks that, along with other collaborators, academic and research libraries become true partners model, for those interested in delving into it more deeply, can be found in a white paper originally written by us in October 2013 and available online. ${ }^{1}$

Our model is based on a handful of assumptions:

1. Current models of OA publishing, especially the APC model, are not scalable and thus are not sustainable. Increasingly the products of research that are required to be shared by funding agencies (e.g., datasets) and forms of research output that are regularly produced (e.g., interactive websites) cannot be accommodated by an object-level one-time payment model. APCs work in disciplines that reward articles; they do not work for other kinds of output.

2. Faculty members and others engaged in scholarly discourse prefer to publish in the venues most relevant to them and their peers, many of which are associated with their scholarly societies. In addition to journals, many of which rank among the top in their field, such venues include books, conference proceedings, discussion forums, society-hosted or sanctioned blogs, societyrecommended data registries, and so on.

3. Sharing the results or products of scholarship generated in academic and research institutions is the responsibility of every such institution.

4. It is the mission of an academic or research library to support the dissemination, collection, organization, and preservation of scholarly output in whatever form it takes.

5. While not every institution or scholarly society has the capacity to build and maintain a publishing enterprise, each has the ability and the responsibility to support those who do. To be a not-for-profit, an organization must meet the requirement that, unlike for-profit businesses, it benefits the public in tangible ways. The mission statements of institutions and societies alike almost invariably include language that commits the organization to, for example, "promot[ing] useful knowledge" (American Philosophical Society) or "convey[ing] the products of its efforts to the world" (Columbia University). Our proposal presents a way forward to allow for collective contribution to the public good.

The OA solution offered in this article encourages partnerships among scholarly societies (and their publishing vendors, such as Cenveo or Sheridan Press, or commercial publishers that provide society services as part of their publishing portfolio, such as Taylor \& Francis or Sage Publications), academic libraries, and other institutional partners (e.g., collaborative e-archives, university presses) to

publish and preserve the research and scholarship that is generated at all institutions, including, but not limited to, monographs and journal articles. Our proposal looks to provide a scalable, fair, responsive, and discipline-independent solution that can be applied to the entire scholarly communication ecosystem in an incremental fashion, rolled out at both small and large scale.

\section{The proposed model: Funding partnerships}

How does the model work?

First there's the money. The funding model we propose, illustrated in Table 1, is based on an annual or multi-year institutional payment made by every institution of higher education, beginning with the US and Canada but (eventually) being requested from every institution that benefits from the research generated worldwide. The institutional payment is based on the number of students and full-time faculty at any given institution adjusted according to a sliding scale tied to the Carnegie/ISCED classification of institutions of higher education (associate's colleges, baccalaureate colleges, master's colleges and universities, and doctorate-granting universities). For non-US 
institutions, an ISCED classification and attendant fees are applied based on the institution's selfreported educational category level. ${ }^{2}$

Table 1. Examples of Institutional Annual Fees

\begin{tabular}{lllll}
\hline Institution & $\begin{array}{l}\text { Carnegie/ISCED } \\
\text { Classification }\end{array}$ & Students & Full-time Faculty & Annual Cost (US\$) \\
\hline $\begin{array}{l}\text { Northwest } \\
\text { College }\end{array}$ & Associate & 2,047 & 79 & $\$ 2,442$ \\
$\begin{array}{l}\text { Gustavus } \\
\text { Adolphus College }\end{array}$ & Baccalaureate & 2,526 & 190 & $\$ 6,002$ \\
Pacific University & Master's & 3,417 & 244 & $\$ 11,471$ \\
UC San Francisco & Medical & 3,137 & 3,237 & $\$ 31,870$ \\
$\begin{array}{l}\text { University of } \\
\text { Pennsylvania }\end{array}$ & Research & 24,725 & 4,718 & $\$ 147,215$ \\
\hline All numbers as of 23 August 2013. & & & \\
\hline
\end{tabular}

Rather than paying per item-level output (e.g., for each article, monograph, or dataset), we propose all institutions contribute to a centrally managed fund at the rate of $\$ 0.50$ per student per year of study, as determined by the aforementioned Carnegie/ISCED classification. An associate's college under our model would pay $\$ 1$ per student per year; a baccalaureate college would pay $\$ 2$; a master's college or university would pay $\$ 3$; and a doctorate-granting university would pay $\$ 5$. In addition, all institutions at all levels would pay $\$ 5$ per year for each full-time faculty member. Administration, staff, part-time faculty, and adjuncts are exempted. The initial per-capita fee schedule was derived by an educated guess as to what the market would reasonably bear in the current economic climate. In practice, this fee structure is likely to vary. An eventual annual fee of 10 times this amount would not be an unreasonable expectation at full implementation of our model, but such an amount would still be well managed by most institutions.

Even for the larger amounts, the annual payment is modest relative to the overall budget of most institutions, but when spread broadly across institutions results in a sum substantial enough to sustain a vibrant and open scholarly communication environment. Of note is that the fees are paid by institutions, not solely by libraries, although in some cases libraries may be the administrative unit tasked with paying, and that many institutions already have funds earmarked for research publication support that could be leveraged for this purpose. The eventual goal would be for library collection budgets to be reallocated to sustain $\mathrm{OA}$ initiatives, diverted toward the purchase of other scholarly materials, or used to support new service initiatives.

Such reallocation of funds can only take place, however, once the institution has committed in the first instance to the payment model. One of the major concerns with OA publishing has been that of so-called "free riders" - those who do not contribute directly to the support of those providing the results of research for free. Because research output is what economists would call a "non-rivalrous good" in which an individual's use of the material does not reduce its availability to others, our model focuses on support for the cost of producing, sharing, and archiving the research and its resulting output - in other words, on the creation of a public good. In the case of our model, the money paid by the institution does not go to purchase content but rather to support the research infrastructure both at the institution and beyond it, in keeping with the institutional mission's public purpose. Because 
the annual fee is based on institutional headcount numbers, the infrastructure it supports can be seen to be supportive of the research done by everyone at the institution, whether students and professors, for the price of a cup of coffee per year. Through their contribution to the collective research ecosystem, institutions can be seen be leaders, rather than be perceived as free riders, a very important motivating factor for most institutions, who do not like to look bad to their peers. In return, institutions receive maximum exposure for work done at their institution and receive the benefit of lowered costs to their students by helping to make available for free use the research that can then be used in teaching and learning, enabling their students to use the materials assigned for their classes without worrying about how they might afford them; reduce the potential liability for institutions who might now be at risk for misuse by their faculty of copyrighted materials they mistakenly believe to be theirs or covered by fair use and use of content in massive open online courses (MOOCs) and other online courses; and gain the potential to attract new students and the best faculty by making readily available the content of their institution as well as by supporting the needs of faculty and students to get access to all materials they need for research, teaching, and learning.

Our model maintains the scholarly communication workflow already in place - data collection, research, and analysis; authoring (both informal and formal); publication and dissemination; and storage, archiving, and preservation - while removing some of the inefficiencies within the system through the elimination of excludability to those resources and opening up access to those materials. In our model, because we ask all tertiary institutions, irrespective of their size or classification, to contribute resources at some level, there should be no free riders among those institutions or the public they serve as part of their mission as institutions of higher education. To ensure that all institutions are properly incentivized to contribute, such mechanisms as institutional rankings and accreditation or reaccreditation criteria, increasingly focused as they are on student skills development and lifelong learning, could be leveraged to reward institutional payments to the $\mathrm{OA}$ fund.

Then there is the mechanism for distribution. As outlined in Figure 1, the institutional payment goes to a centrally managed fund that is used to provide direct support for the production, distribution, access, and long-term archival preservation infrastructure of the partnerships. Institutions and scholarly societies apply for the funds through a competitive grant process. Preference will be given to those proposals that provide for both the widest possible use and reuse of content (e.g., those proposing a Creative Commons Attribution License would be weighted more heavily that those proposing Creative Commons Attribution-Non-Commercial-No Derivatives, although neither would be automatically excluded), and to those that propose cost savings through implementing electronic workflows and other efficiencies. Because the goal of this program is sustainability, grants are openended so that recipients are guaranteed a reliable source of income. At the same time, adherence to strict guidelines, transparency, and oversight of the funding are required. 


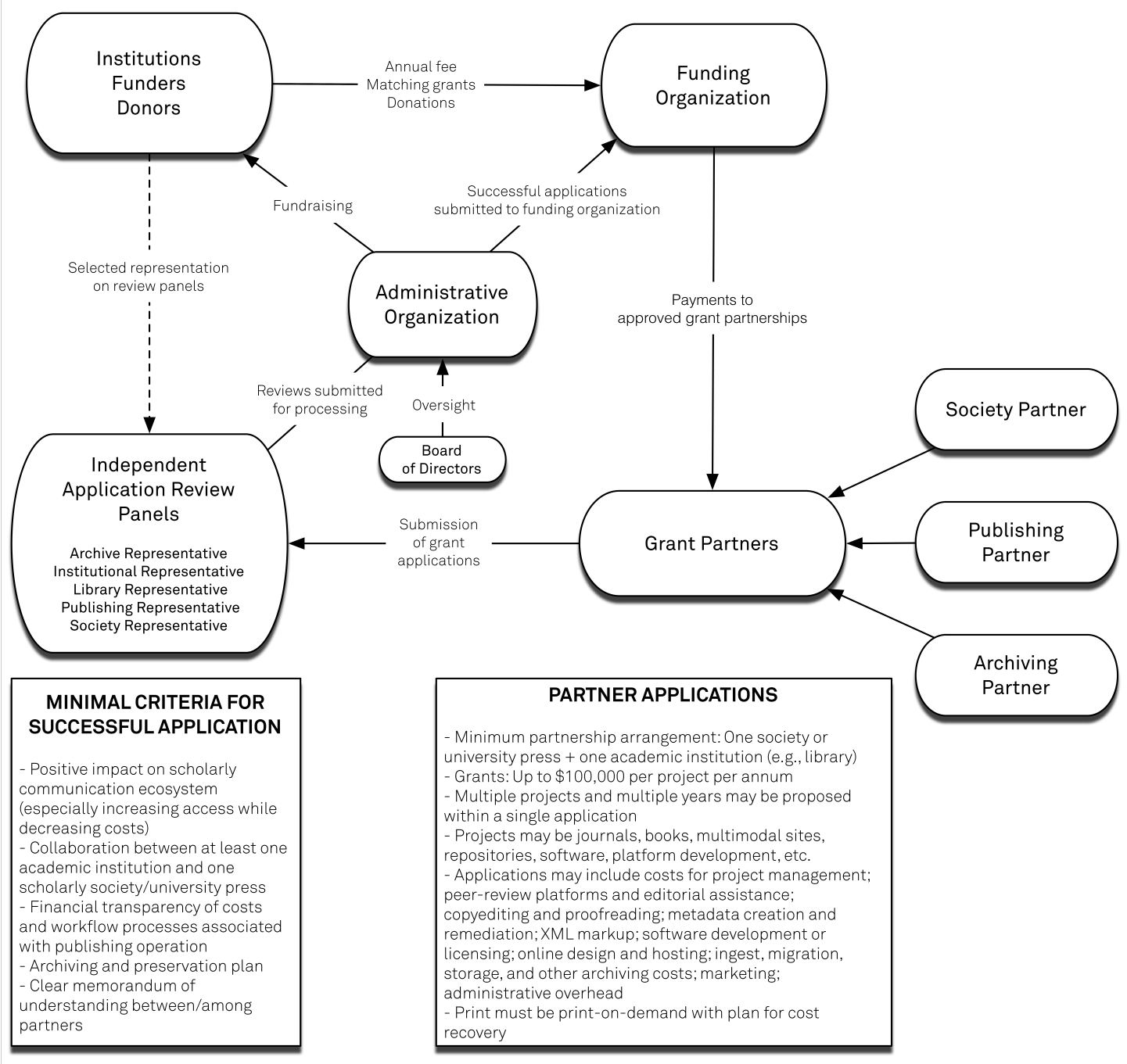

Figure 1. Proposed Model's Application and Funding Workflow

While the goal is long-term sustainability, our plan also recognizes that evolution in scholarly communication is important and inevitable. Partnerships are non-binding and may be dissolved when it no longer makes sense for them to exist; however, measures must be taken to ensure that the published product is preserved.

\section{The proposed model: Role of scholarly societies}

Kathleen Fitzpatrick, Director of Office of Scholarly Communication at the Modern Language Association, has eloquently described that society's vision of the role of the scholarly societies in this era:

We all - scholars, libraries, and societies - share the goal of increasing the wealth of knowledge that we hold in common. And if we focus on that collective goal, a viable path forward can be forged. There is still reason for some benefits of membership in a scholarly society to be exclusive to members if we rethink the role of the scholarly society in the digital age. The shifts [in scholarly communication brought about by technology] require us to consider the possibility that the locus of a society's value in the process of knowledge 
creation may be moving from providing closed access to certain research products to instead facilitating the broadest possible distribution of the work done by its members. This is a profound change, and not just for societies but for their members: we may in coming years operate under a model in which, rather than joining in order to receive the society's journal, one instead joins a society in order to get one's own work out to the world, surrounded by and associated with the other work done by experts in the field. ${ }^{3}$

Our proposal looks to bring this vision to reality, and we consider both the steady presence and changing role of societies vis-à-vis their membership as being key to the success of the model we propose. Recent Ithaka S+R Faculty Surveys, one in the United States ${ }^{4}$ and one in the United Kingdom, ${ }^{5}$ found that $75 \%-90 \%$ of faculty are members of at least one scholarly society, with half being members of more than one. What these faculty members most value about their societies is the society-facilitated exchange of information with their peers, whether by attending conferences, reading scholarly publications, or engaging in informal professional communication via blogs or listservs. Understandably, according to these surveys, faculty at all levels, but especially junior faculty, look to their societies to provide respected venues for this communication and the imprimatur they need for enhancing their credentials within their disciplines, whatever form it takes. One could assume that opening up communication more broadly, under the auspices of one's scholarly society, as Fitzpatrick suggests, would be welcomed by that society's membership.

Like their members, societies believe their primary role is facilitating the exchange of information, but many society staff view that role more in terms of "disseminating information" than in the activities of "coordinating a body of peer interaction" and "networking" that seem to be most prized by their members; in a 2012 survey of societies conducted by Allen Press, ${ }^{6}$ more than $85 \%$ of respondents indicated that they considered publishing to be their most important role. Because of this focus, the greatest challenge for a society in shifting from subscription- or membership-based publishing to $\mathrm{OA}$ is often not philosophical, but financial. Societies and the services they offer their members are often overly dependent on publishing revenue, including journal income, and in the Allen Press survey, an "overwhelming 70\%" viewed OA as both "an opportunity and a threat." This tension is reflected in Figure 2, which shows that of the 988 publications from 765 societies that we analyzed for our white paper during the summer of 2013, barely $10 \%(99 / 988)$ were freely available online, only slightly more than were available as print-only subscriptions (71/988). The professional staff's sometimes almost exclusive focus on the society's traditional publishing operations, on its journals and books, offered often as subscriptions and frequently only via print, rather than on the core mission of the society - the advancement and dissemination of knowledge itself - is a position that increasingly puts them at odds with their own members. 


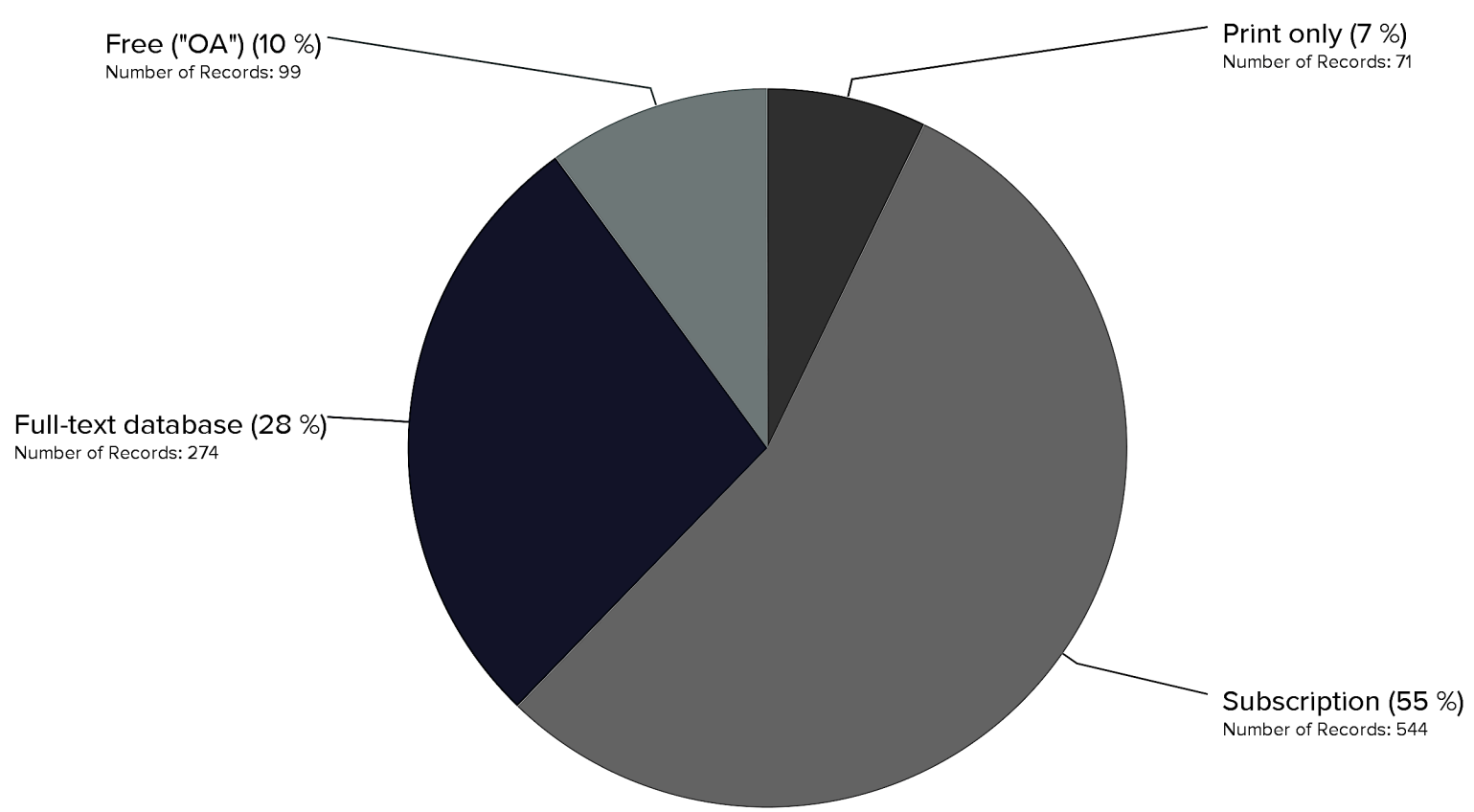

Figure 2. Serials Publishing Operations of Sample Societies

To gain an understanding of society publishing practices for our white paper (see http://bit.ly/1lLMIPx), we analyzed 765 societies and their 988 serials publications, drawn from nine "umbrella" organizations: the American Academy of Religion and its affiliated societies; the American Anthropological Association and its affiliates; the organizations that comprise the American Council of Learned Societies; the American Historical Association and its affiliates; the American Political Science Association and its affiliates; the Association for Slavic, East European, and Eurasian Studies and its affiliates; the College Art Association and its affiliates; the Modern Language Association and its affiliates; and the journals in included in the online fulltext database BioOne, a not-for-profit collaborative of independent society and scholarly publishers in the biological sciences. Although our focus in this white paper has been on HSS, we have included journals from BioOne as a first step toward showing that our model can work in the STEM environment.

This figure shows the provision of online access across these society publications. Within our sample, only $10 \%$ of the publications are currently available online without a subscription; $7 \%$ of publications have no online version at all, even as part of a full-text database (e.g., ProQuest, EBSCO). More information can be found in the Appendices to the white paper.

While the challenges in moving to $\mathrm{OA}$ are considerable, they can be overcome, particularly in partnership with others. Publishing consultant Raym Crow of the Chain Bridge Group has identified the typical challenges facing society publishing operations:

Most society publishers face structural constraints - including insufficient market leverage, low tolerance for risk, undercapitalization, and lack of specialized business expertise - that prevent them from sustaining themselves effectively in an increasingly competitive market for academic journals, thus jeopardizing the sustainability of society publishing in the longterm.

He has urged the creation of "publishing co-operatives," which he argues would "have the potential to provide a powerful financial and organizational model that will allow society publishers to serve their dual imperatives of honoring their missions while remaining financially sustainable."7

Our model builds upon Crow's, but is more targeted. We suggest bringing those very societies most struggling with OA - HSS societies - together with publishing partners best suited to provide those services that are the most difficult for these societies to fulfill, particularly online hosting, search engine optimization, and long-term archiving. Although our model does not prescribe a particular publishing partner and societies may wish to retain the arrangements they already have with a commercial publisher or vendor or to join forces with a larger self-publishing society, we suggest 
that suitable partners could also be found within the academic and research library community, especially those libraries that already have well-established publishing operations, such as those who make up the Library Publishing Coalition. Many of these libraries currently host online peerreviewed journals and regularly develop and support original digital content projects of all kinds and are capable of providing the backend infrastructure needed. Still residing with the society would be the editorial functions: soliciting and handling submissions, managing peer review, accepting materials for publication that pass review, and overseeing copyediting. Current inefficiencies in the publishing process could be streamlined through technology partnerships, rather than the current system of client-vendor relationships, that would provide cost-effective peer-review systems, online hosting platform support, and a commitment to long-term preservation, moving the responsibility for archiving or migrating digital materials for future use from the societies to the academic libraries, who have always had access to and preservation of materials as their core mission.

Also critical to our model is its extensibility to other forms of scholarly communication beyond journal articles. Our model would encourage partnerships that would further enhance the valued role of communication facilitator played by the society, with the technology-focused publishing partner(s), for example, providing subject-specific or data repository services, supporting informal communication platforms (e.g., blogs), and advising on and hosting of multimodal works - all offered under the auspices and with the imprimatur of the society or society coalitions. One of the takeaways from the Allen Press survey is that in recent years there has been very little movement among societies to move entirely to an online-only offering, despite libraries' desiring such an outcome. The partnerships we suggest here would allow for the best of both worlds. The publishing partner would provide online access to the global community of readers; the society could continue to provide print as a member-only benefit.

So what is the value proposition for societies to adopt our model? We believe societies that do so would see the following benefits:

- Broader exposure to publications and thus more visibility for the society

- The possibility of attracting more (especially younger) members, who value $\mathrm{OA}$ as a priority in their publishing and will join societies that support that value

- Renewed focus of the society on mission effectiveness

- Freedom to choose mission-aligned publication and operational partners, rather than restricting choice to those offering merely the best monetary incentive.

\section{The proposed model: Role of the institution}

While many universities and colleges are well positioned to play a leading role in a new scholarly communication ecosystem, not all have the capacity to support even the most basic institutional repository, let alone a major scholarly publishing enterprise. Nevertheless, every institution of higher education, the researchers and scholars they employ, and the students they educate would benefit from wide and unfettered access to the information that is produced and distributed by all tertiary institutions. Small- and medium-sized state universities, private liberal arts colleges, and community colleges, as well as government agencies, hospitals, and other independent research centers, have a vested interest in and - we would argue - the responsibility to support OA publishing every bit as much as do large research-intensive universities.

In the model we propose here, the fundamental role of the institution, as we have described it above, is to provide financial support through an annual payment based on the number of its full-time faculty and its student population to support the shift from subscription to OA publishing. For those institutions whose libraries are partnering with societies to launch or expand their publishing operation, the institution should offer guidance and support for library administrators as they restructure their organization to support these new endeavors. Institutions and their administrators should encourage recognition and acceptance of new modes of scholarly communication as criteria for faculty hiring, tenure, and promotion, thereby supporting the full range of scholarly output 
produced by their researchers.

In return, what do the institution and its administrators get?

- Because support for research infrastructure is based on institutional headcount numbers, the institution can be seen to be supportive of both its students' and its faculty's research for the price of a cup of coffee per person per year. As both faculty and students increasingly support OA, they would see this contribution to be a small price to pay to make OA a reality.

- OA provides maximum exposure for the work of the institution, in keeping with the mission most have to share the products of their research with the world.

- Not only can contributing institutions be seen as leaders in opening up the world's research to the public, but just as governments have begun to recognize the value of $\mathrm{OA}$, factoring it into funding requirements, so may institutional ranking organizations and accreditation bodies, who are increasingly likely to factor OA contributions into their criteria.

- Global adoption of this model will lower costs to students by making available all research output for use in teaching and learning.

- A scholarly communication ecosystem that is broadly OA lowers the risk for institutions who can now be held liable for in advertent misuse of copyrighted materials and allows for unfettered content in MOOCs and for other educational forms of reuse.

- The institution may attract new students and the best faculty by making readily and freely available to them the quality research of their institution as well as being recognized for supporting the needs of faculty and students to get access to all materials they need for research, teaching, and learning.

\section{The proposed model: Role of the library/consortia}

While institutions of higher education are responsible for generating knowledge and understanding, it is the libraries or consortia of libraries that operate within and among those institutions that actively engage in collecting, preserving, and providing access to the scholarly and creative output that is generated. For decades now, librarians, administrators, and scholars have railed against the runaway costs of commercial publishing of scholarly content. More recently, academic and research libraries and consortia have taken on the additional responsibility - for many, if we are honest, the burden - of supporting OA initiatives, from developing their own OA publishing endeavors to assisting faculty with payments for APCs. We believe it is time for academic and research libraries to reverse this untenable trajectory and instead focus their resources on reclaiming their historic role in curating, preserving, migrating, and providing ongoing access to the scholarly record. We believe libraries and consortia have a key role to play in shaping a new and evolving information landscape.

Our proposal capitalizes on the existing institutional repository and digital publishing infrastructures that many academic and research libraries have in place to support an expanding OA publishing enterprise. By partnering with scholarly societies, academic and research libraries fulfill their mission to capture and preserve the intellectual capital generated by our institutions while avoiding the resistance of faculty to deposit the products of their scholarship in repositories.

Another key role for libraries/consortia will be to ensure that content is preserved (in "dark" archives) and migrated for ongoing access ("light"). At the local level, many large academic and research libraries already provide access to and maintain the integrity of digital content, as well as all related metadata (such as administrative, technical, and preservation), in their institutional repositories and digital libraries or archives in accordance with standard preservation principles. This approach allows institutions to maintain control over the entire preservation process for faculty's, researchers', and students' work and for all other content they own. Drawbacks to such a strategy, however, include the expense of onsite staff and technology for digital preservation and the limited range of geographic distribution offered by a centralized operation. Approaches to digital curation and preservation currently underway include independent and integrated efforts by 
institutions and libraries to protect scholarly output nation and worldwide, as well as commercially driven approaches developed beyond the institution and library.

We contend that all of these efforts - both in publishing and preservation - place the academic and research library in what we would argue is its rightful place in the scholarly communication ecosystem. While we believe all libraries will benefit from the move to $\mathrm{OA}$, we also recognize that not all academic or research libraries are in a position to develop the kind of publishing partnerships proposed here. Nevertheless, the role these libraries play within their organizations will continue to evolve from one of a gateway to subscription collections to one of enhanced and engaged instructional and research support.

We recognize that moving to a new model of scholarly communication has the potential to alter the mission of every college and university library in profound and lasting ways. We further acknowledge that these new roles are not without challenge and would require the transformation of many traditional library departments and functions, as well as the roles and responsibilities of current staff. In addition to providing the back-end technical infrastructure, libraries/consortia could be called upon to take on new roles, including, but not limited to:

- Management of vendor relationships, such as online hosting services, abstracting and indexing services, online-peer review systems, print-on-demand vendors, and others.

- Development of new discovery services.

- Implementation of metadata and other knowledge organization enhancements (e.g., microdata, linked data, search engine optimization).

In the recent Ithaka S+R/JISC/RLUK UK Survey of Academics, ${ }^{4}$ one of the key findings noted that "Academic libraries collections are most likely to be seen as an important source for providing journal articles and books for research and teaching purposes, but following closely in second place are freely available materials online." OA will happen. Our proposal offers academic and research libraries the opportunity to play a leading rather than supporting role in the scholarly communication ecosystem.

So what exactly are value propositions in our proposal for academic and research libraries?

- In the earliest phase, we readily admit that there are no significant savings to be found, but every society that converts its list to $\mathrm{OA}$ will eventually mean savings for libraries not only individually but collectively. As many libraries already subsidize OA initiatives with no decrease to their collections costs, this proposal provides real hope for tangible savings downstream.

- This model offers academic and research libraries the chance to embrace their mission to expand access to information in support of teaching, research, and scholarship. Libraries can shift from their main function as that of gatekeeping to that of curation and preservation.

- Our plan enables every library at every institution to contribute toward this new scholarly communication ecosystem and be recognized for their contribution through new systems of institutional ranking and accreditation.

\section{The proposed model: Phased approach}

We believe that the route to successful adoption of the approach we are advocating is to demonstrate its attractiveness and sustainability through a stepwise implementation process.

We will begin by identifying or establishing a nonprofit organization or a partnership of organizations well positioned to implement the plan, especially in terms of being able to provide infrastructure support (e.g., financial systems) - ideally, a group or consortia recognized for global $\mathrm{OA}$ advocacy and as leaders in innovative OA endeavors, able to lend credibility to this endeavor.

We will at the same time identify academic and research libraries or library consortia best positioned 
to support an OA publishing and archiving endeavor, along with scholarly societies willing to partner with those libraries to either build up their OA publishing operation or to convert their current subscription-based publishing enterprises to OA.

The final step in this launch-phase process will be to develop a timeline for implementation that illustrates how the cost of support for OA publishing will eventually reduce overall costs while maintaining the quality of the research output and expanding access to it.

Phase 1 demonstrates the proof of concept by converting some HSS society publications to OA. The goal of this phase is threefold: (1) get buy-in from a number of institutions and societies, (2) obtain ongoing funding and partnership commitments from those organizations, and (3) test the assumptions of our model in practice. Success in this proof-of-concept phase will lead naturally into Phase 2.

Phase 2 expands the practical implementation of our model to demonstrate it can operate at scale. We will market the model broadly to degree-granting institutions, still focusing our efforts on North America but expanding to include more globally representative institutions, and include more publishing partnerships.

Phase 3, the full implementation phase, expands funding to include that from industry, foundations, public libraries and secondary schools, governmental agencies, and the public and includes all countries; markets the model to all tertiary institutions worldwide; leverages a fully developed and tested "matchmaking" mechanism to provide connections and create partnerships between and among institutions, societies, and libraries at a global scale; and broadens the application and review process for proposals to include all comers, from any discipline and from any publisher.

\section{Summary of the proposal's key components}

We conclude by summarizing the five most important components of our proposal:

1. While our model would fund tradition formats for publication, such as articles and monographs, we are also trying to think anew how to fund the entire scholarly communication infrastructure. Because none of us can predict what new forms of communication will arise in the next few years, our model looks for a way to support whatever those new modes may be.

2. We are suggesting putting together societies, institutions, and libraries in collaborative ways that have not been tried before, at least not at scale.

3. We are focusing in the first phase on HSS. For all the problems inherent in an APC OA funding model, in science, technology, engineering, and mathematics (the STEM fields) the APC model has been shown to work, at least on the current scale. In HSS the needs and challenges are different.

4. We are looking to the institutions themselves, earmarked by their chancellors, presidents, or provosts, not simply to their libraries, to fund this model. The numbers we quote may look large to a college or university library, but are quite small at institutional scale, at least for most countries in North America, Europe, and Oceania.

5. We want full participation from the entire higher education community, from small community colleges and large research universities alike. As everyone will benefit from a world in which all research output is freely available, everyone should pitch in to make this the reality.

A bold rethinking of the economics of $\mathrm{OA}$, our plan is nevertheless designed to assuage the fears and embrace the investments of the stakeholders in the scholarly communication system. It is intentionally incremental, acknowledging the inherent conservatism of academia. Our model enables 
societies to have the financial freedom to develop the strategies they need to continue to provide their members with services that are useful and meaningful. It suggests preservation and curation should be a primary role for libraries, because this is a natural space for libraries to occupy and has always been part of their mission. It allows all the partners in the scholarly communication ecosystem to begin to work together to agree on best practices, not just for infrastructure, metadata, etc., but for business practices as well. It provides a clear but ever-evolving and expanding roadmap to address concerns about "free riders," including a campaign to involve all tertiary institutions, raise endowment funds from public libraries and foundations, accept donations from the public, and otherwise engage all beneficiaries - very much in keeping with the core mission of academic institutions, societies, and libraries: the advancement of knowledge and learning and communication of the products of those efforts to the entire world. And just as research and scholarship are increasingly global and collaborative, our plan is not bound by national borders but can - and we hope will - be adopted in all countries by those looking for a more equitable and sustainable $\mathrm{OA}$ model.

The current models of OA publishing are not scalable and not sustainable. Sharing, curating, and preserving scholarship, results, and data are imperative for the advancement of research in the humanities and sciences alike. Deep structural changes to the publishing system are not only a necessity to respond to the current funding crises in higher education and the emerging forms of scholarship in the digital age, but also to foster and deepen the connections between the academy and the wider public. Only a model that builds collaborative alliances across the wide variety of institutions on a global scale can develop a fair and equitable path to truly open and sustainable forms of producing, curating, publishing, and preserving scholarship in our rapidly changing world.

\section{References}

1. Kennison, R. and Norberg, L. 2014. A scalable and sustainable approach to open access publishing and archiving for humanities and social sciences. New York, K|N Consultants, http://bit.ly/1lLMIPx (accessed 30 May 2014).

2. See ibid, Table C1: Institutional, http://bit.ly/1jo9Ya0 (accessed 9 February 2014). US numbers for faculty and students come from the Integrated Postsecondary Education Data System (IPEDS) (nces.ed.gov/ipeds/). Canadian numbers for students come from Association of Universities and Colleges of Canada's statistics (http://www.aucc.ca/canadian-universities/facts-andstats/enrolment-by-university/), which rounds to the nearest 10 , and for faculty are from a variety of sources, including institutional websites, annual reports, etc. Other numbers for international institutions are from similarly public sources, including the Higher Education Statistics Agency (http://www.hesa.ac.uk/) for UK numbers. All figures are as of 23 August 2013.

3. Fitzpatrick, K. 2013. Statement on public access to federally funded research. New York, Modern Language Association, http://scholcomm.commons.mla.org/statement-on-public-access-tofederally-funded-research (accessed 29 September 2013).

4. Housewright, R., Schonfeld, R. C., and Wulfson, K. US Faculty Survey 2012. New York: Ithaka S+R, 2013 ,

http://www.sr.ithaka.org/sites/default/files/reports/Ithaka_SR_US_Faculty_Survey_2012_FINAL.pdf (accessed 28 November 2013).

5. Schonfeld, R. C., and Wulfson, K. Ithaka S+R / Jisc / RLUK: UK Survey of Academics 2012. New York, Ithaka S+R, 2013, http://sr.ithaka.org/research-publications/ithaka-sr-jisc-rluk-uk-surveyacademics-2012 (accessed 28 November 2013).

6. Tillery, K. 2012 Study of Subscription Prices for Scholarly Society Journals: Society Journal Pricing Trends and Industry Overview. Lawrence, KS, Allen Press, 2012, 
http://allenpress.com/resources/education/jps (accessed 3 October 2013).

7. Crow, R. 2006. Publishing cooperatives: an alternative for society publishers. First Monday, 11(9): http://firstmonday.org/issues/issue11_9/crow/index.html (accessed 19 February 2013). 